\title{
The Identification of the Potential of Game-based Learning in Vocational Education within the Context of the Project "Play the Learning Game"
}

\author{
http://dx.doi.org/10.3991/ijet.v8i1.2359 \\ J. Pauschenwein, E. Goldgruber and A. Sfiri \\ FH JOANNEUM, University of Applied Sciences, Graz, Austria
}

\begin{abstract}
Game based-learning exploits the potential of ICT and games engage learners. The objectives of the European project "Play the Learning Game" are to spread and update the results of the "Learning Game Portal" to vocational education teachers and trainers. The 10 transnational partners develop and execute trainings, intend to disseminate the project contents as broadly as possible and promote a transnational discussion among teachers and trainers focusing on the exploitation of the educational potential of multimedia and videogames.
\end{abstract}

Blended learning workshops addressed to Austrian vocational education teachers and trainers are organised to make use of the Learning Game Portal and simultaneously test and describe the usefulness of the contents for their own teaching or training.

Index Terms_-game-based learning, vocational training, teacher training

\section{INTRODUCTION}

\section{A. Game-based learning}

Each year more and different e-learning training products (training courses, training platforms etc.) are developed but most of these products do not exploit the full potential of ICT as contents and methodologies are still the result of adapting the traditional approaches of education and training to the new digital context.

The NMC Horizon Report 2012 which aims to "identify and describe emerging technologies likely to have an impact on learning, teaching, and creative inquiry in higher education" (Johnson 2012) [1], describes gamebased learning as one of two significant trends in the midterm horizon (2-3 years).

Already in 2001 Prensky [2] stated that learning and playing are fundamentally related and that games engage learners. In the case of videogames and multimedia the development of contents and the enhancement by technology collude.

What is important to learning is not only the entertainment factor of games, but "the identification of the ludic aspects of learning and the learning experience at play together with their application of natural junctures are fundamental to game-based learning” (Kröger and Breuer 2011) [3]. Therefore it is central to link gaming features to learning objectives.

\section{B. Games and Learning}

Furthermore Game-based learning supports modern learning theories. In games learners participate and experiment in secure virtual environments (Activity Theory), learners experience different situations (Situated Learning), and learners learn through direct experiences based on their interactions in the game (Experiential Learning) (Tang et al. 2009) [4].

The Manual for the application of Videogames and Multimedia for educational and training purposes ${ }^{2}$ states in chapter four that "games can be a forum where learning arises as a result of tasks stimulated by the content of the games, knowledge is developed through the content of the game, and skills are developed as a result of playing the game.”

There are some guidelines offered and different approaches are discussed to find out skills and competences are needed to carry out one of them. The different ways to include games in teaching or training are:

a) Integration of a ready-made videogame into the didactical design.

b) Adaption of a ready-made videogame in order to add elements, or contents that will support the desired learning processes.

c) Design of a videogame and integration of this developed game into the teaching practice.

d) Support learners to design a videogame that facilitates the desired learning processes to reach learning objectives.

\section{THE PROJECT "Play THE LeARNING GAME"}

The LLP Leonardo da Vinci - Transfer of Innovation project "Play the Learning Game" is funded by the European Commission and the Spanish National Agency OAPEE and lasts for two years. It aims to extend, exploit and transfer the results of the former Sokrates Comenius project "The Learning Game", which resulted in an online collection of reviewed video games and multimedia for educational purposes in the Learning Game Portal.

The objectives of "Play the Learning Game" are the creation of an international network of vocational education teachers and trainers interested in the innovative and effective use of Multimedia and Videogames for educational purposes, the identification of useful multimedia and video games for learning and the training of teachers 
PAPER

THE IDENTIFICATION OF THE POTENTIAL OF GAME-BASED LEARNING IN VOCATIONAL EDUCATION WITHIN THE CONTEXT OF THE PROJECT "PLAY THE LEARNING GAME"

and trainers to give them the necessary skills to make use of games and enable them to let their students and training participants "play" within educational context.

\section{A. Reviews of eLearning and videogames}

Within the "Play the Learning Game" project in a first step the collection of material was revised, new multimedia and video games that have educational and training potential and e-learning sources to implement innovative technical solutions for education and training were identified and the teachers' training manual on the development of videogames for educational purposes was updated. The updated content is disseminated on the "Play the Learning Game" website and will be tested by teachers and trainers of the partner countries over the project period.

The website includes a searchable database of videogames that have been evaluated and are categorized according to their type, genre, games visual perspective, language, the availability of an editor, the amount and type of players as well as an explanation on how the videogame can be used in an educational context. Each of the 10 project partners contributed 25 additional reviews. One of the identified games with an excellent usability potential in education is e.g. "Ludwig" 3 which is an adventure game for learning physics in different environments, which are suited to the curriculum.

Additionally the collection of reviews of eLearning based teaching materials focusing on main subject areas has been supplemented equal in extent and can be found on the website. "Mein Körper und ich"4 is e.g. an eLearning product that covers different approaches to the human body and was evaluated very good overall. Among other things it is excellent in teaching usability, educational and learning value as well as quality and relevancy of content.

\section{B. The training manual}

The teachers' training manual is divided into six chapters and covers several topics in the context of game-based learning. The first chapter provides an introduction to the main issues addressed by the manual and presents each of the following chapter contents concerning Education, Multimedia, Videogames, Programming and Social Networks. Chapter two deals with education connected with eLearning and new learning technologies. The third chapter addresses the connection between multimedia and new learning technologies. The fourth chapter explains how and why videogames are used in learning processes, as teachers have to make a critical reflection about the topic treated in order to plan efficient and effective educational programmes. The next chapter explores the topic of mobile learning and presents a programming language. And finally the last chapter deals with social games in education. The manual is translated in English, Spanish, German, Italian and Greek.

\section{Training activities}

The organisation of workshops addressed to vocational education teachers and trainers aims to test the Learning Game Portal and to focus on their acquisition of the necessary skills to exploit the potential of multimedia and videogames for education and training.

3 http://www.learningame.org/videogames/scheda.php?id=607 4 http://www.learningame.org/database/scheda.php?id=400
The partners update the concept for the blended-training and transfer it into their didactical approach. The trainings will take place from autumn 2012 until spring 2013. Per partner 60 teachers and trainers are invited to participate in three trainings. In the first phase the trainees will explore the Play the Learning Game portal, they will comment reviews of games useful for education and study the manual about potential and impact of game-based learning in schools and company training. In the second phase the trainees will have the possibility to get in contact with the training participants in other countries and they will share their ideas about scenarios for gamebased learning in schools and companies. Therefore a discussion forum on the portal is established and a virtual conference is conducted during the intermediate workshop among the transnational groups of teachers and trainers.

Furthermore a group of participants especially interested into the topic will be supported to design and program a small learning application that results in a pilot course.

\section{The TRAINING}

The aims of the blended training are the examination of the manual and the materials on the portal, engagement in the use of game-based learning in school and to gain an insight into the theory of game-based learning. Furthermore the partners support the creation of an own game as a group work.

The blended trainings which will last for four weeks give an insight in the potential and possibilities of gamebased learning and motivate the participants to review games of the Learning Game Portal and explore the integration of serious games into their teaching and training scenarios. It deepens the understanding of teachers and trainers of the potential of multimedia solutions and videogames in education and training.

\section{A. Training design}

At the beginning of the training an introductory workshop is conducted. Teachers and trainers that are interested in innovative didactic concepts and like the "learning by playing" approach get introduced in the project and the theory of game-based learning.

Then a three week online phase follows, where the participants get in touch with the materials provided on the portal. In this phase the participants also have to fill in some of the necessary evaluation forms concerning the project materials. Therefore six so called e-tivities are provided which cover the project requirements and help the teachers and trainers in the case of self-study. E-tivities according to Gilly Salmon are small online tasks that engage learners and support collaboration [5].

After these three weeks an intermediate workshop takes place and the acquired experiences are brought together. During this face-to-face workshop easy tools are presented to build small games and the participants discuss their ideas for games. Furthermore a virtual meeting is conducted, where the teachers and trainers attend the distance meeting in videoconference in order to enhance the transnational discussion. Therefore the workshop is organized in parallel among at least two countries during which the participants discuss the contents of the Learning Game Portal. In each testing group one teacher or trainer acts as the spoke person for the group. 
The training ends with an online phase, which lasts for one week and supports the creation of a small game sequence. Furthermore a reflection of the training and the training design takes place.

\section{B. Steps to design a game}

The following steps are a brief version of the guidelines suggested by Pivec and Sfiri [6] in combination with the insights won during the discussions at the Game Design workshop offered at the Kick off meeting of the Project "Play the Learning Game" in Florence, in December 2011. The trainees - teachers and trainers - will be supported in the collaborative design of a learning game and will:

1. Decide on the learning objectives: What should players learn? What is the learning content? This will help to define the type and the characteristics of the game in order to achieve the specific learning objectives.

2. Situate the learning activity in a model game world. Here it is important to think of an appropriate story within meaningful situation, time and space for the educational game and to consider aspects and game characteristics

3. Proceed with the elaboration of the storyline and the screenplay, dealing with the issues of learning objectives. To engage players a narrative structure and additional characters are essential.

4. Incorporate underlying pedagogical support. As it is important to maintain the appropriate level of difficulty throughout the game support in regard to challenges must be managed.

5. Design possibilities for decision taking. At that point preconceive the look and feel of the game environment and decide on developing tools.

6. Conceive and design the interface. Materials like photographs and videos have to be collected and prepared. Therefore objects, actors, devices and software needed to realize the interface have to be considered.

7. Implement and evaluate the game. The ideas have to be transferred into a prototype and subsequently some tests have to be performed.

\section{EXPERIENCES}

The first training groups have started in October / November and the project experiences so far point out that teachers and trainers are quite receptive to a game-based learning approach. In a workshop around game-based learning during the eLearning Day at FH JOANNEUM the participants said that they are highly motivated to play in their teaching or training. Further presentations of the project at national and international conferences found positive responses and active discussions about the importance of game-based didactics for learning.

On the other side it is not easy for teachers and trainers to integrate a new didactical approach into their day-today work because of a lack of time, practical experience, suitable games and tools as well as underlying circumstances in the educational system. There exists already a large training programme for Austrian teachers and they plan their training nearly a year in advance. These trainings are managed by the technical system "PH Online". We succeeded to integrate the training into $\mathrm{PH}$ Online but it didn't increase the number of interested teachers.

In general it is difficult to integrate a two years project into the deadlines of a school year. The first project year was used for the preparation of the training and it would be easy to start the dissemination activities when the materials, concepts and online material are ready. It is not easy to advertise training courses when the preparation is not finished and it is difficult to find interested teachers or trainers during a school year when all other activities are already planned.

In the first Austrian training group we encountered quite different expectations on the training. Part of the participants was satisfied by the more theoretical approach whereas one participant was eager to start with the programming of a game without taking time for the design. In this first group we didn't notice different needs of teachers and trainers.

\section{SUMMARY}

In the LLP "Play the Learning Game" we aim to spread the content of the Play the Learning Game-Portal and we will support teachers and trainers to understand the potential of a game-based learning approach with respect to their field of work and try to enhance their capability to use and integrate videogames and Multimedia in order to make learning more attractive.

Based on the great work of the former Sokrates project and on the excellent cooperation with the partners we developed useful and interesting materials on the "Play the Learning Game" website. In the second project year we want to disseminate the projects' materials and concepts as broadly as possible. Although the topic of the project is challenging we want to ensure on this way that classes and trainings in schools and companies will further develop and will include ICT in a "playful" way.

\section{REFERENCES}

[1] L. Johnson, S. Adams, and M. Cummins, The NMC Horizon Report: 2012 Higher Education Edition. Austin, Texas: The New Media Consortium, 2012. http://www.nmc.org/publications/ horizon-report-2012-higher-ed-edition

[2] M. Prensky, Digital game-based learning. New York, London: McGraw- Hill, 2001.

[3] S. Kröger and A. Breuer, „Der Einsatz von Unterhaltungsspielen in der Schule,“ in Spielen und Erleben mit digitalen Medien, A. Winter, Ed. München, Germany: Ernst Reinhardt, 2011, pp. 123144.

[4] S. Tang, M. Hanneghan, and A. El Rhalibi, "Introduction to Games-Based Learning,” in Games-Based Learning Advancements for Multi-Sensory Human Computer Interfaces: Techniques and Effective Practices, T. Connolly, M. Stansfield and L. Boyle, Eds. Hershey, PA: Information Science Reference (IGI Global), 2009, pp. 1-17.

[5] G. Salmon, E-tivities. London: Kogan Page Limited, 2002.

[6] M. Pivec and A. Sfiri, "How to implement a game in an educational context," in Guidelines for Game-based Learning, M. Pivec, A. Koubek and C. Dondi, Eds. Germany: Pabst Science Publishers, 2004, pp. 92-114. 


\section{AUTHORS}

Jutta Pauschenwein is with the ZML - Innovative Learning Scenarios, FH JOANNEUM, University of Applied Sciences, Graz, Austria (e-mail: jutta.pauschenwein@fhjoanneum.at).

Eva Goldgruber is with the ZML - Innovative Learning Scenarios, FH JOANNEUM, University of Applied Sciences, Graz, Austria (e-mail: eva.goldgruber@fhjoanneum.at).

Anastasia Sfiri is with the ZML - Innovative Learning Scenarios, FH JOANNEUM, University of Applied Sciences, Graz, Austria (e-mail: anastasia.sfiri@fhjoanneum.at).

The Play The Learning Game project N²011-1-ES1-LEO05-35968, is funded by the European Commission and by the Spanish National Agency OAPEE in the framework of the Lifelong Learning Programme - Leonardo Da Vinci Sub-programme - Transfer of Innovation. This project has been funded with support from the European Commission. This publication reflects the views only of the authors, and the Commission cannot be held responsible for any use which may be made of the information contained therein. This article was modified from a presentation at the International Conference of Interactive Computer Aided Learning ICL2012, September 2012 in Villach, Austria. Received 15 November 2012. Published as resubmitted by the authors. 